\title{
Susceptibility of Neisseria gonorrhoeae to Quinolones and Azithromycin: Its Implication in the Treatment of Pharyngeal Infection
}

\section{Aguirre-Quiñonero A*, Rodríguez-Achaerandio A, Calvo-Muro F and Canut-Blasco A}

Servicio de Microbiología, Instituto de Investigación Biosanitaria, Hospital Universitario de Álava, Bio Araba, Vitoria-Gasteiz, Spain

${ }^{*}$ Corresponding author: Amaia Aguirre-Quiñonero, Servicio de Microbiología, Instituto de Investigación Biosanitaria, Hospital Universitario de Álava, Bio Araba, Vitoria-Gasteiz, Spain, Tel: 945 007564; Fax: 945 007555; E-mail: amayiaguirre@gmail.com

Received date: August 02, 2018; Accepted date: August 22, 2018; Published date: August 29, 2018

Citation: Aguirre-Quiñonero A, Rodríguez-Achaerandio A, Calvo-Muro F, Canut-Blasco A (2018) Susceptibility of Neisseria gonorrhoeae to Quinolones and Azithromycin: Its Implication in the Treatment of Pharyngeal Infection. Arch Clin Microbiol Vol.9 No.4:84

Copyright: (c) 2018 Aguirre-Quiñonero A, et al. This is an open-access article distributed under the terms of the Creative Commons Attribution License, which permits unrestricted use, distribution, and reproduction in any medium, provided the original author and source are credited.

\section{Short Commentary}

Neisseria gonorrhoeae infections are the second most common bacterial sexually transmitted infections (STI) in our area [1-3]. Resistance to this microorganism is currently considered a global threat by the World Health Organization (WHO). Current Spanish guidelines recommend a dual therapy with extended-spectrum cephalosporines (such as cefotaxime, ceftriaxone, cefuroxime or cefixime) and azithromycin (AZT) [4]. Dual therapy has shown synergy in-vitro and in-vivo and is effective against Chlamydia trachomatis. In pharyngeal infections cephalosporins have shown to be less effective than quinolones; thus, UK guideline recommend ciprofloxacin (CIP) in pharyngeal infection if the isolate is known to be quinolone susceptible. On the other hand, European and German guidelines recommend quinolones as an alternative treatment in pharyngeal infections if the isolated strain is susceptible to these compounds and there are indications against using ceftriaxone [5].

Between January 2015 and December 2017, a total of 111 clinical strains of $N$. gonorrhoeae were isolated at the Microbiology Laboratory of the University Hospital of Álava (Vitoria-Gasteiz, Spain). CIP and AZT susceptibility data for all these strains was recorded and is currently being analyzed in order to determine the CIP-and AZT resistance rates among $N$. gonorrhoeae. Patients age and sex was also analyzed. Information regarding patients sexually orientation was not available. For this analysis, one isolate per patient was considered. The majority of gonococci $(90.1 \%)$ were collected from men. The age range was 14 years to 68 years, with a median age of 32.1 years. All strains were susceptible to cefotaxime and only $7(6.31 \%)$ were cefuroxime nonsusceptible (Figure 1).

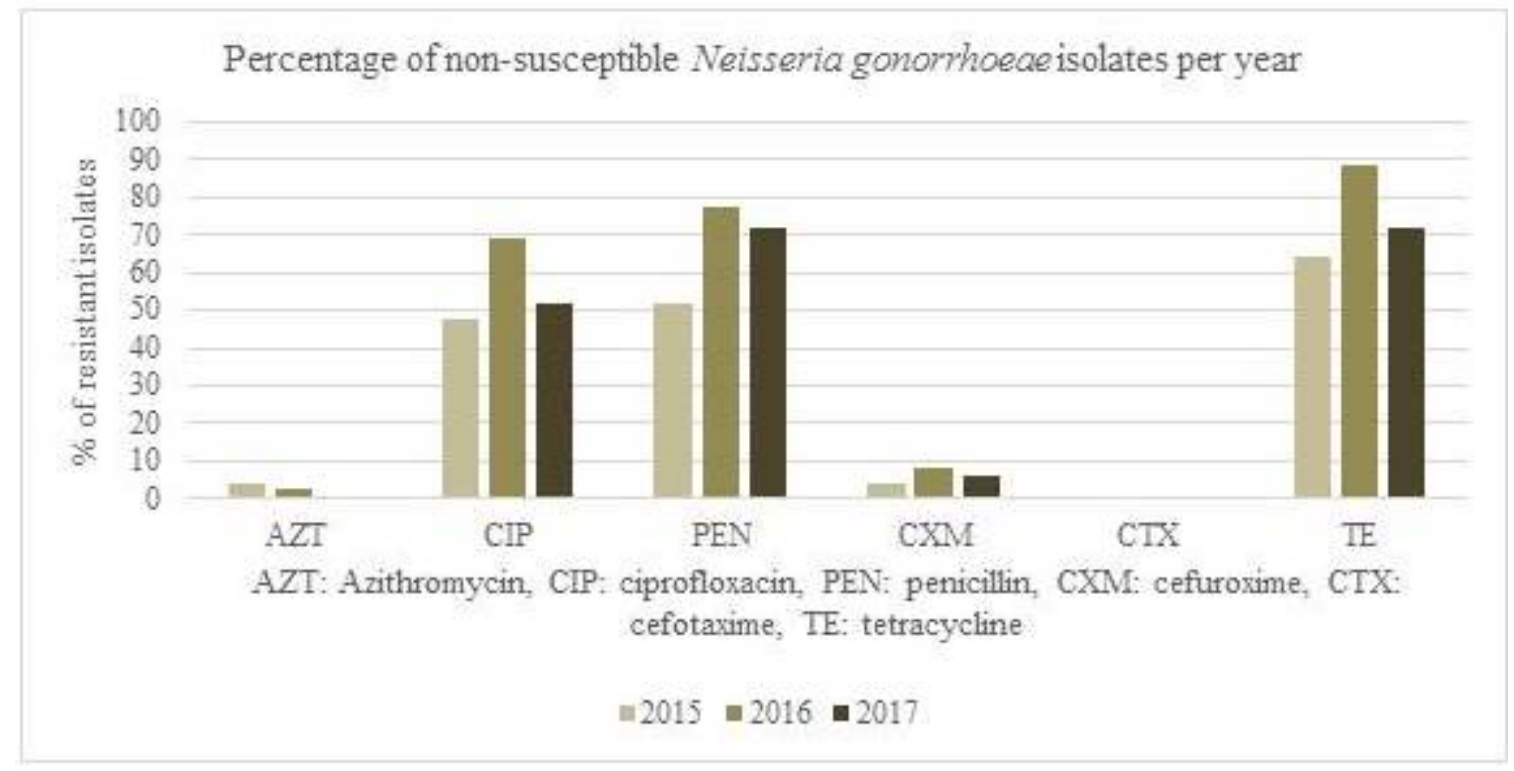

Figure 1 Percentage of resistant Neisseria gonorrhoeae isolates per year at the Microbiology Laboratory of the University Hospital of Álava (Vitoria-Gasteiz, Spain), January 2015-December 2017 ( $n=111$ isolates). 
As far as CIP is concerned, following Clinical 41 and Laboratory Standards Institute (CLSI) interpretative criteria, which defines the CIP susceptibility breakpoint at $<0.06 \mathrm{mg} / \mathrm{L}$, $63(56.8 \%)$ of the strains evaluated were CIP-non-susceptible; 61 (55.0\%) were CIP-resistant and 2 (1.80\%) CIP-intermediate. CIP-resistant strains were isolated from patients with a mean age of 33.0 years old and were $93.4 \%$ men.

In our analysis and similar to what Ota et al., [6] have stated before, CIP-non 47 susceptible strains were more resistant to penicillin (non-susceptible rate of $85.7 \%$ ) and to tetracycline (non-susceptible rate of $92.1 \%$ ). Interestingly, Serra-Pladevall et al., [7] have recently found that CIP resistance rates were higher in heterosexual patients than in men who have sex with men.

Regarding $\mathrm{AZT}$, current $\mathrm{CLSI}$ recommendations do not provide a susceptibility breakpoint but an epidemiological cutoff value defined at $>2 \mathrm{mg} / \mathrm{L}$ for non-wild- $N$. gonorrhoeae. Thus, AZT susceptibility is interpreted following European Committee on Antimicrobial Susceptibility Testing (EUCAST) guidelines, which defines the resistant breakpoint at $>0.5$ $\mathrm{mg} / \mathrm{L}$. Taking this breakpoint into account, only two strains displayed minimum inhibitory concentrations (MICs) above the susceptibility breakpoint defined at $0.25 \mathrm{mg} / \mathrm{L}$; the two of them harboured a MIC of $0.5 \mathrm{mg} / \mathrm{L}$ and would be classified as non-susceptible.

This report aims to highlight the increase of quinoloneresistant $N$. gonorrhoeae strains in the last 3 years. Our date provides further evidence that quinolones should no longer be recommended as first line therapy although in pharyngeal infections cephalosporins have shown to be less effective. In fact, if the isolated strain is known to be susceptible to quinolones, some guides recommend ciprofloxacin is these infections [2].

Only two of the analyzed strains harboured 64 nonsusceptible-AZT MICs but the finding is worrisome since AZT is part of the currently used empiric regimen.

Although molecular methods are increasingly replacing conventional culture procedures, the latter are crucial in order to determine susceptibility patterns.
We would like to emphasize the importance of surveillance programs to control the emergence of these resistant strains, particularly the AZT-resistant ones, in order to update treatment recommendations and to avoid therapeutic failures.

Harmonized criteria for susceptibility testing and interpretation are needed to provide accurate advice to clinicians as well as to obtain reliable epidemiological information at local, regional or national levels.

\section{References}

1. Serra-Pladevall J, Barberá-García MJ, Roig-Carbajosa G, JuvéSaumell, González-López JJ, et al. (2013) Neisseria gonorrhoeae: resistencias anti-microbianas yestudio de la dinámica poblacional. Situación en 2011 en Barcelona. Enferm Infecc Microbiol Clin 31: 579-583.

2. Díaz A, Herrando I, Díez M (2013) Resistencias antibióticas de Neisseria gonorrhoeae: Una situación emergente. Bol Epi Sem 21: 178-192.

3. Cobo F, Cabezas Fernández MT, Cabeza-Barrera MI (2016) Antimicrobial susceptibility and typing of Neisseria gonorrhoeae strains from Southern Spain, 2012-2014. Enferm Infecc Microbiol Clin 34: 3-7.

4. Bignell C, Unemo M (2013) European STI Guidelines Editorial Board: 2012 European guideline on the diagnosis and treatment of gonorrhoeae in adults. International Journal of STD \& AIDS 24: 85-92.

5. Unemo $M(2015)$ Current and future antimicrobe treatment of gonorrhoeae continues to challenge. BMC Infect Dis 15: 364-375.

6. Ota KV, Jamieson F, Fisman DN, Jones KE, Tamari IE, et al. (2009) Prevalence of and risk factors for quinolone-resistant Neisseria gonorrhoeae infection in Ontario. CMAJ 180: 287-290.

7. Serra-Pladavall J, Barberá MJ, Callarisa AE, Bartolomé-Comas R, Andreu A (2017) Differences in Neisseria gonorrhoeae population structure and antimicrobial resistance pattern between men who have sex with men and heterosexuals. Epidemiol Infect 145: 379-385. 